\title{
Engelli Bireylerin Topluma Entegrasyonu İçin Binalar Uygun mu? Ankara Örneği
}

\author{
Gül Deniz YILMAZ YELVAR ${ }^{1}$ \\ ${ }^{\text {I}}$ Turgut Özal Üniversitesi Fizik Tedavi ve Rehabilitasyon Yüksekokulu, Ankara, Türkiye \\ e-mail: guldenizy@yahoo.com
}

\section{Özet}

Rehabilitasyonda Uluslararası fonksiyon sinıflaması bireyin vücut ve yap1 fonksiyonları, aktivite ve katılımdan kaynaklanan özürlülüğü belirlemede kullanılmaktadır. Ulaşılabilirlik, engellinin topluma entegrasyonu açısından önemlidir. $\mathrm{Bu}$ kapsamda çalışmamızın amacı Türkiye'nin başkenti olan Ankara'da sağlıklı bir bireyin günlük yaşantısında kullandığı binaların engelli bireyler açısından ulaşılabilirliğini değerlendirmektir. Veriler bireylerin sıklıkla kullanma ihtimali olan 58 binadan toplandı. Binalar Ankara şehir rehberinden basit rasgele örnekleme yöntemiyle seçildi. Anayoldan erişim, rampa, kaldırım, otopark, asansör ve bina içinin engelli için tasarımı ile ilgili bilgiler kaydedildi. Elli sekiz binadan toplanan verilere göre, binaların \%56.9'u anayola erişim, 20.7'si binaya girişte uyarıcı zemin, 21.6'sı rampa eğimi, otoparkı olan binaların \%14.3'ü ise otopark genişliği açısından uygun bulundu. Binaların hiçbirinde duvara yaklaşıldığında uyarıcı zemin bulunmamaktaydı. .Bu çalışmada değerlendirilen binaların engelli ulaşımı için uygun olmadığı sonucuna varılmıştır. Engelli bireylerin sıklıkla ziyaret ettikleri binaların ulaşılabilirliğinin sağlanması onların topluma katılımı açısında önemlidir.

Anahtar Kelimeler: ulaşılabilirlik, nörorehabilitasyon, aktivite, katılım, toplumsal bariyerler

\begin{abstract}
In the rehabilitation setting, the ICF can be used to identify a person's impairment in body function and structures, activity and participation. Accessibility is important in terms of community integration of the disability people The purpose of this study was to assess the accessibility to buildings that used in daily life by a disabled person in Ankara which is the capital city of Turkey. Data were collected from 58 buildings that commonly used in daily life by people. Buildings were selected randomly from Ankara city quide. The instrument used was a survey form covering six accessibility areas: main road, ramps, sidewalks, parking, entarence and building's interior design for disabled. According to the data collected from 58 buildings, $56.9 \%$ of the building in terms of access to the main road, $20.7 \%$ of them in terms of stimulant surface at the enterence of the build, $21.6 \%$ of them in terms of ramp slope and $14.3 \%$ of them in terms of disabled parking width were appropriate. None of the building, near the wall do not have surface stimulus. This study concluded that buildings which were assessed is not suitable for disabled accessibility. It is important to ensure the accessibility to building that was frequently visited by disabled people in terms of community integration of them.
\end{abstract}

Key Words: accessibility, neurorehabilitation, activity, participation, community barriers 


\section{Giriş}

Binalar ve mimari yapılar direk ya da dolaylı olarak insanların kullanımına sunulmak amacıyla inşa edilmektedirler. Bununla birlikte birçok engelli için bu yapılara ulaşmak zor ya da imkansız şekildedir (Ezeukwu et al., 2011). Oysa engelli bir bireyin topluma katılımında ulaşılabilirlik en temel hak ve özgürlüktür.

Mimari engeller özürlü bireylerin sosyal statü değişiklikleri, sosyal izolasyon, ekonomik yaşantıda kısıtlanma, yaşam alanı seçeneklerinde sınırlılık, fonksiyonel bağımsızlıkta ve yaşam kalitesinde azalmaya neden olmaktadır (Bengtsson, 2005). Bireyin sadece evinde yaşantısını sürdürmesinin yerine ulaşılabilir bir çevrede yaşamasının pek çok pozitif ve tedavi edici etkileri olmaktadır. Yaşam alanlarının dizaynı bireyin bütün ihtiyaçlarını karşılayacak çeşitlilikte ve kullanıcılar için güvenli olması gerekirken, ev dışı alanlarda bireyin bağımsızlığında problemler yaşanmakta bu durum bireyin yaşam alanlarına katılımını etkilemekte ve özürlü birey için bağımlı bağımsızlık kavramını gündeme getirmektedir (Engstrom and Nordeson, 1995).

Dünya Sağlık Örgütünün Uluslararası fonksiyon, özür ve sağlığın sınıflandırılması 3 ana komponentten; vücut yapı ve fonksiyonları ( fizyolojik, anatomik düzey), aktivite ( birey düzeyinde yapılan görevler) ve katılım ( sosyal yaşam içindeki bireyin düzeyi) oluşmaktadır. Sınıflandırmada bireyin çevre ile etkileşim içinde olmasının fonksiyonellik açısından önemli olduğu ve bu etkileşimin tanımlanması gerekliliği vurgulanmaktadır. Etkileşimin anlaşılması yapıların kullanımında kolaylaştırıcı ya da bariyer oluşturabilecek faktörlerin belirlenmesi için de önem teşkil etmektedir (York, 2009).

1 Temmuz 2005'te çıkarılan 5378 sayılı Özürlüler ve Bazı Kanun ve Kanun Hükmünde Kararnamelerde Değişiklik Yapılması Hakkında Kanun'un geçici ikinci maddesinde 'Kamu kurum ve kuruluşlarına ait mevcut resmi yapılar, mevcut tüm yol, kaldırım, yaya geçidi, açık ve yeşil alanlar, spor alanları ve benzeri sosyal ve kültürel alt yapı alanları ile gerçek ve tüzel kişiler tarafindan yapılmış ve umuma açık hizmet veren her türlü yapılar bu Kanunun yürürlüğe girdiği tarihten itibaren yedi yıl içinde özürlülerin ulaşılabilirliğine uygun duruma getirilmelidir.' Denilmektedir.

Bu kapsamda çalışmamızın amacı Türkiye'nin başkenti olan Ankara'da sağlıklı bir bireyin günlük yaşantısında kullandığı binaların tekerlekli sandalye kullanan ve görme özürlü bireyler açısından ulaşılabilirliğini değerlendirmektir.

\section{Yöntem}

Veriler sağlıklı bireyin kullanma ihtimali olan kamu binası, hastane, alışveriş merkezi, restaurant, kültür merkezi, eczane, muayenehane, ibadethane ve tiyatrodan oluşan toplam 58 binadan toplandi. Binalar Ankara şehir rehberinden basit rastgele örnekleme yöntemiyle seçildi. Mimarlar Odası tarafından hazırlanan Mimari Projelerde Engelli ve Yaşlılarla İlgili Olarak Uyulması Gereken Temel kuralların bulunduğu Ulaşılabilirlik Kılavuzu'na (Olguntürk, 2007) göre aşağıdaki parametreler değerlendirildi:

Anayoldan erişim: Tekerlekli sandalye kullanan bireylerin, araçtan inip bina girişine kadar olan mesafe ile bina girişi değerlendirildi. Kılavuza göre tercih edilen mesafe 50 m.den daha fazla olmamalıdır. Bina girişinde uyarıcı ve kaymaz zemin varlığı ile bina giriş genişliği değerlendirildi. Giriş genişliğinin en az $150 \mathrm{~cm}$ olması gerekmektedir.

Rampa: Girişinde rampa olan binaların rampa eğimleri ve genişliği değerlendirildi. Normal standartlara göre rampa eğimi $\% 5$ ile $\% 10$ arasında değişmelidir, genişliği ise $130 \mathrm{~cm} . n$ in altına düşmemelidir.

Kaldırım: Kaldırım yüksekliği $\mathrm{cm}$ cinsinden ölçüldü, rampa varlığı ve genişliği ile kaldırım üzerindeki uyarıcı zemin varlığı değerlendirildi. Beklenen kaldırım yüksekliği $6-15 \mathrm{~cm}$ arasında olmalıdır ve tekerlekli sandalyenin çıkabilmesi için kaldırımın uygun yerlerinde en az $140 \mathrm{~cm}$ genişliğinde rampa olmalıdır. 
Otopark: Engelli otoparkın varlığı ve her bir park yerinin genişliği değerlendirildi. Otoparkların $\% 2^{\prime}$ lik kısmı engelli bireylere ayrılmış olmalıdır ve her bir park yerinin genişliği $350 \mathrm{~cm}$ x $500 \mathrm{~cm}$ olmalidir.

Asansör: Asansör girişinde uyarıcı zemin ve eşik varlığı değerlendirildi.

Bina içinin engelli için tasarımı ile ilgili bilgileri değerlendirmeye alındı. Duvar kenarlarına 12 $\mathrm{cm}$. kala uyarıcı zemin varlığı, merdiven genişlikleri ve yükseklikleri ile engelli tuvaleti varlığ değerlendirildi. Merdiven genişliği en az $30 \mathrm{~cm}$. ve yüksekliği $15 \mathrm{~cm}$. olmalıdır.

İstatistiksel analiz için Windows tabanlı SPSS 15 analiz programı kullanılmıştır. Ölçümle belirlenen değişkenler için ortalama \pm standart sapma, sayımla belirlenen değişkenler içinde (\%) ve frekans değerleri hesaplandı

\section{Sonuçlar}

Altı kamu binası, 9 hastane, 9 alışveriş merkezi, 2 restaurant, 2 kültür merkezi, 6 eczane, 4 muayenehane, 6 ibadethane 2 tiyatro, 3 otel, 6 üniversite ve 3 belediye binasından oluşan toplam 58 bina değerlendirildi. Değerlendirme parametrelerine göre binaların uygunluğu Tablo 1'de gösterilmektedir.

Anayoldan erişim: Anayoldan erişim mesafesi 50 m.nin altında olan 33 bina tespit edildi. 25

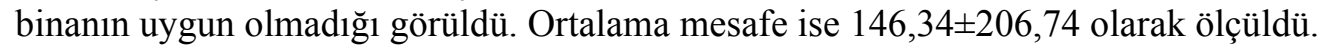

Rampa: Bina girişinde rampa olan 37 binanın rampa genişliği ortalaması 107,23 $\pm 169,48 \mathrm{~cm}$ ve eğimi $16,12 \pm 10,23$ olarak ölçüldü.

Kaldırım: Kaldırım yüksekliği $11,93 \pm 7,23 \mathrm{~cm}$ ve rampa genişliği $117,77 \pm 107,19 \mathrm{~cm}$ olarak ölçüldü.

Otopark: Otoparkı olan 39 binanın 21'inde engelli otopark yeri mevcutken, sadece 3 tanesi standartlara uygun bulundu.

Asansör: Asansörü olan 56 binanın sadece 3 tanesinde asansör girişinde uyarıcı yüzey varlığı tespit edildi.

Bina içi tasarımı: 31 binanın engelli tuvaleti vardı. Binalardan hiçbirinin duvarlara yaklaşırken uyarıcı yüzeyi bulunmamakta idi.

Tablo 1 Binaların Ulaşılabilirlik Kılavuzu’na göre uygunluğunun değerlendirilmesi

\begin{tabular}{|l|c|c|c|c|}
\hline $\mathrm{n}=58$ & UYGUN \\
$\mathrm{n}$ & $\%$ & $\begin{array}{c}\text { UYGUN } \\
\text { OLMAYAN } \\
\mathrm{n}\end{array}$ & $\%$ \\
\hline Anayoldan erişim en fazla 50 metre & 33 & 56.9 & 25 & 43.1 \\
\hline Binaya giriş uyarıcı zemin varlığı & 12 & 20.7 & 46 & 79.3 \\
\hline Rampa var & 37 & 63.8 & 21 & 36.2 \\
\hline Rampa eğimi \% 5-10 arasında & 8 & 21.6 & 29 & 78.4 \\
\hline Rampanın genişliği 120 cm ve üstü & 24 & 64.8 & 13 & 35.2 \\
\hline Kaldırımda uyarıcı yüzey varlığı & 16 & 27.6 & 42 & 72.4 \\
\hline Kaldırım yüksekliği (6-15 cm) uygun olan & 37 & 63.8 & 11 & 18.2 \\
\hline Kaldırım rampası varlığı & 41 & 70.7 & 17 & 29.3 \\
\hline Kaldırım rampasının genişliği(140cm ve üstü) & 24 & 58.5 & 17 & 41.5 \\
\hline
\end{tabular}




\begin{tabular}{|l|c|c|c|c|}
\hline Otopark varlığı & 39 & 67.2 & 19 & 32.8 \\
\hline $\begin{array}{l}\text { Engelli otopark varlığı } \\
\text { (Toplam otoparkın \% 2'si oranında) }\end{array}$ & 21 & 53.9 & 18 & 47.1 \\
\hline Engelli otopark genişliği uygun olan (350*500cm) & 3 & 14.3 & 18 & 85.7 \\
\hline Bina girişi kaymaz zeminden oluşuyor & 12 & 20.7 & 46 & 79.3 \\
\hline Asansör girişinde uyarıcı yüzey varlı̆̆ & 3 & 6.5 & 43 & 93.5 \\
\hline Giriş genişliği $150 \mathrm{~cm}$ üstü & 43 & 74.1 & 15 & 35.9 \\
\hline Engelli tuvalet var & 31 & 53.4 & 27 & 56.6 \\
\hline Duvar kenarlarına $12 \mathrm{~cm}$ kala uyarıcı yüzey varlığı & 0 & 0 & 0 & 0 \\
\hline Merdiven genişliği $30 \mathrm{~cm}$ ve üstü olan & 18 & 31.0 & 40 & 69.0 \\
\hline Merdiven yüksekliği $15 \mathrm{~cm}$ olan & 17 & 29.3 & 41 & 70.7 \\
\hline
\end{tabular}

\section{Tartışma}

Çalışmada sıklıkla ziyaret edilen toplam 58 bina değerlendirmeye alınmış ve binaların engelli bireyler ulaşımı için uygun olmadığı sonucuna varılmıştır. Değerlendirilen binaların hiçbiri \%100 uygun bulunmamıştır. Aktivite ve katılımın önündeki en önemli engellerden biri olan ulaşılabilirlik engelli bireylerin topluma entegrasyonunu zorlaştırmaktadır.

Çalışmamızda engelli bireyin ulaşım aracından inip binaya giriş yapana kadar ulaşılabilirliği incelendiğinde uygun olmayan kaldırım yüksekliği, rampaların olmaması var olan rampaların ise genişlik ve eğimindeki uygunsuzluk ve anayoldan erişim uzaklığı bireylerin topluma katılımı için bariyer oluşturmaktadır. Bekçi'nin Bartın ilini inceledikleri çalışmalarında sadece engelli bireyin değil sağlıklı bireyinde evinden çıktığ 1 andan itibaren mimari engellerle karşılaştıkları belirtilmektedir. Kaldırımlardaki kot farkları, yüksek eğimli rampalar, zemin döşemelerindeki uygulama hataları, güvenlik önlemleri alınmaksızın yapılan alt yapı inşaatlarının engellileri daha engelli hale getirdikleri, sağlıklıların ise hareketlerinin kıstlanmasına neden olduğu vurgulanmaktadır (Bekçi, 2012). Ordu ilindeki bir sokağın değerlendirildiği çalışmada yol boyunca rampaların olduğu rampa öncesinde uyarıcıların olduğu ancak yükseklik, genişlik açısından standartlara uymadığı rapor edilmiştir (Akbaş ve Atabeyoğlu, 2015).

Useh ve ark.nın 20 binayı inceledikleri çalışmalarında bina girişleri açısından tekerlekli sandalye ile ulaşılabilirliği değerlendirdiklerinde \% 80 uygunluk bulmuşlardır (Useh, 2001). Bizim çalışmamız da benzer şekilde \% 74.1 olarak rapor edilmektedir.

Otopark incelemesi yapıldığında, binaların \% 67.2'sinde otopark bulunmaktadır. Var olan otoparkların yarısında engelli park yeri bulunmakta ve bunlardan sadece 3 tanesinin normal standartlarda olduğu görülmüştür. Akbaş ve Atabeyoğlu'nun çalışmasında inceledikleri sokak boyunca yer alan otoparklarda engelliler için park yerinin bulunmadı görülmektedir (Akbaş ve Atabeyoğlu, 2015). Useh ve ark.nın çalışmasında binaların bir çoğunun engelli otoparkına sahip oldukları ve bir tanesinin uygun genişlikte olmadığını bildirmişlerdir (Useh, 2001). Otoparkın uygun genişlikte olmaması özellikle tekerlekli sandalye kullanan bireyin manevra alanını daraltmasına ve ulaşılabilirliğini zorlaştırmaktadır.

Binaların iç tasarımlarında da ulaşılabilirlik açısından uygunluk çok az bulunmuştur. Hiçbir yapıda duvarlara yaklaşırken uyarıcı zeminlerin bulunmaması özellikle görme engelli bireyler için tehlike teşkil etmektedir.

Çalışmanın bazı limitasyonları da bulunmaktadır. Çalışmamızda bina yapıların ulaşılabilirliği Mimarlar Odası tarafından hazırlanan Mimari Projelerde Engelli ve Yaşlılarla İlgili Olarak Uyulması 
Gereken Temel kuralların bulunduğu Ulaşılabilirlik Kılavuzu göre yapıldı. İleriki çalışmalarda bu alanları kullanan engelli bireylerin kullanım kolaylık/zorlukları yüz yüze görüşme yöntemiyle belirlenip memnuniyetleri değerlendirilebilir.

Sonuç olarak Ankara ilindeki binaların değerlendirilmesinde ulaşılabilirliğin yeterli olmadığı gözlenmiştir. Nörorehabilitasyonda bireyin bağımsızlı̆̆ farklı aktivitelere ulaşabilme ve topluma içerisindeki rollerini yerine getirmeye bağlıdır. Dolayısıyla kentsel yapılar engelli bireyin daha engelli hale gelmeyeceği, sağlıklı bireylerin de kısıtlanmadan mobilitesine izin verecek şekilde planlanmalıdır. Planlama sürecinde meslek disiplinleri birlikte çalışarak engelli bireylerin kamu ve özel alanlarda uygun yaşam alanları oluşturmalı ve toplumun tamamının ihtiyaçlarının eksiksiz karşılanması hedeflenmelidir. Bu bağlamda bakıldığında engellilerin topluma entegrasyonu, iş gücüne katkıda bulunmasıyla sosyal ve ekonomik açıdan da ülkenin gelişimine katkıda bulunacakları düşünülmektedir.

\section{Kaynaklar}

AKBAŞ, H. B., ATABEYOĞLU, Ö. 2015. Sırrı Paşa (Fidangör) Yaya Bölgesinin Engelli Kullanımı Açısından Ulaşılabilirliğinin Değerlendirilmesi. ARTIUM, 3, 37-53.

BEKÇİ, B. 2012. Fiziksel engelli kullanıcılar için en uygun ulaşım akslarının erişebilirlik açıdan irdelenmesi: Bartın kenti örneği. Bartın Orman Fakültesi Dergisi, 14, 26-36.

BENGTSSON A. 2005. Outdoor environments at three nursing homes: Focus group interviews with staff. Journal of Housing for the Elderly, 19, 49-69.

EZEUKWU, A.O., EDET, L.I., UKAEJIOFO, A.C. 2011. Accessibility of persons with mobility disability to public buildings in enugu metropolıs, Nigeria. Continental J. Biomedical Sciences, $5,33-40$

Engstrom B and Nordeson A. 1995. What neurological patients regard as quality of life, Journal of Clinical Nursing, 4, 177-183

OLGUNTÜRK N., Türkiye'de Özürlüler İçin Ulaşılabilirlik Mevzuatı, Dosya 04. 2007. TMMOB Mimarlar Odası Ankara Şubesi.

USEH, U, MOYO, A. M., MUNYONGA M. 2001. Wheelchair accessibility of public buildings in the central business district of Harare, Zimbabwe. Disability and Rehabilitation, 23, 490-496

YORK, S. L. 2009. Residential design and outdoor area accessibility. NeuroRehabilitation, 25, 201208 